\title{
Foreign Minister of Uzbekistan says hopes for dialogue on water disputes in Central Asia
}

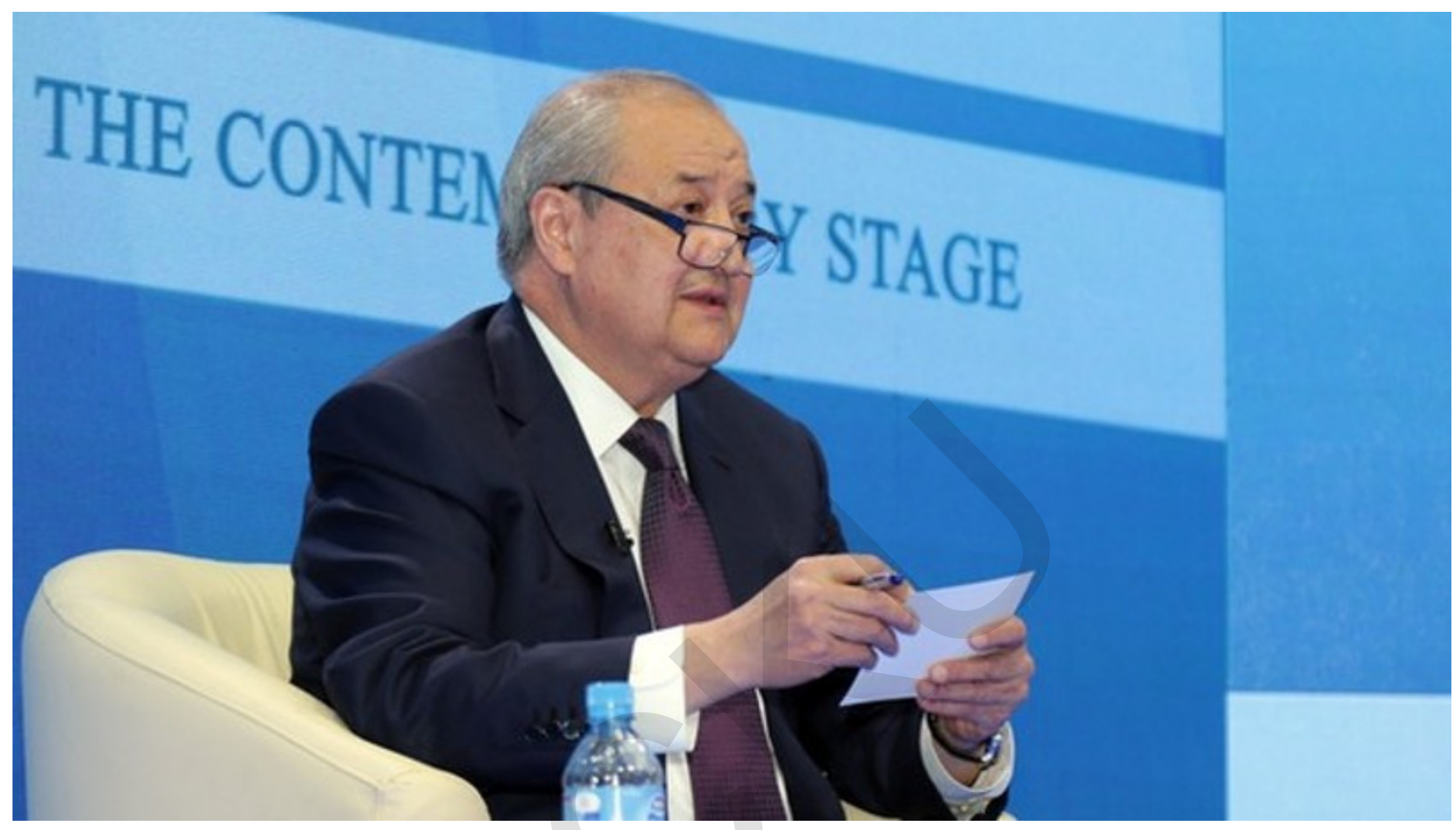

AKIPRESS.COM - The United Nation's proposal on water resource management in Central Asia will hopefully allow to start a dialogue for resolution of the problem, said Foreign Minister of Uzbekistan Abdulaziz Kamilov on April 14 speaking in a press conference in Tashkent.

The diplomat told that the United Nations Regional Centre for Preventive Diplomacy in Central Asia (UNRCCA) has sent the Amu Darya and the Syr Darya conventions to all regional countries, as well as to the U.S., Russia, the World Bank and other countries and the international organizations.

“The preliminary acquaintance with these conventions shows quite reasonable approaches to resolution of this very complex issue. I hope that our neighbors will pay attention to this UN's proposal and we will be able to start a mutually interested dialogue," said Kamilov.

The Foreign Minister believes that the regional countries should sign an 
agreement on water use on the basis of international mechanisms of regulation of the disputed issues, as well as compensation for damage.

According to him, the sides will have to do hard work during discussion of this issue, but he hopes they will be able to achieve progress.

Uzbekistan earlier opposed the construction of hydropower plants in Tajikistan and Kyrgyzstan.

Then-Prime Minister of Uzbekistan Shavkat Mirziyoyev earlier sent a letter to his Tajik colleague Kohir Rasulzoda, where he reminded that the official Tashkent had strongly opposed the completion of construction of the Rogun hydropower plant on the Vakhsh River.

The Uzbek side blamed environmental and economic risks of the construction of hydropower plants on the Vakhsh river. 